 \\ 岁 PEP III
}

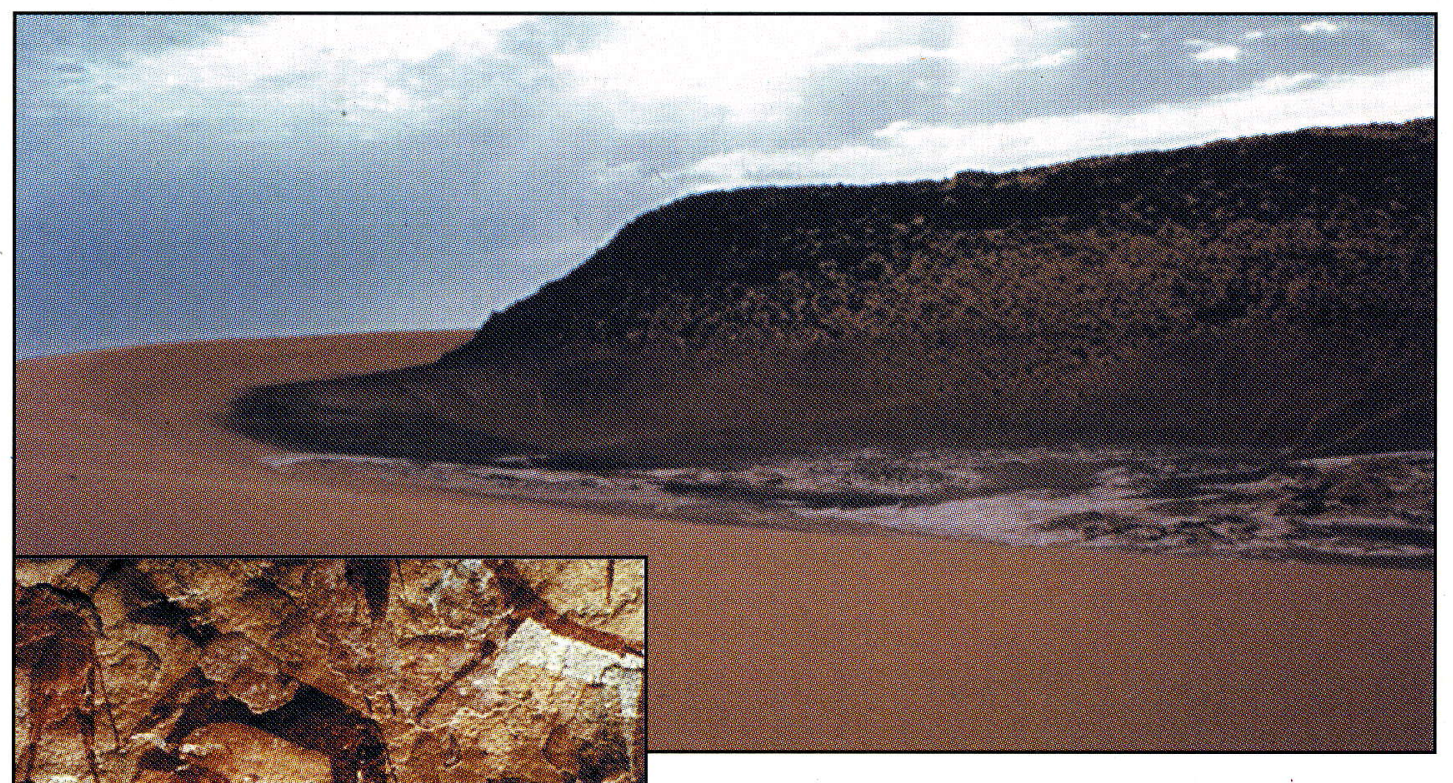

One of the most dramatic responses to climate change along PEP III has been hydrological change in the Sahara-Sahel. The area of the Tin Ouaffadene groundwater-fed paleolake in the Ténéré desert was inhabited 10,000-6000 years ago. (Photo: F. Gasse)

\section{The Paris-Bierville Workshop}

12 - 15 September, 1996

This meeting was supported by IGBP-PAGES, START, the European Science Foundation, the US National Science Foundation, the French CNRS, the INQUA-PAGES Paleomonsoon Project and MEDIAS-FRANCE. It was organized by MEDIAS-FRANCE and the Paleoclimate team of URACNRS, 723 (Orsay, France).

The primary purpose of the Meeting was to stimulate, prioritize and coordinate the work of the leading paleoenvironmental researchers in the region of the PEP III Transect, in line with the intentions set out in the PANASH Project document (PAGES Report, 1995-1). The meeting brought together 78 scientists from 24 countries and was a major landmark in the advancement of the PEP III objectives.

It allowed the PEP III leaders to:

- summarize the state-of-the-art in relation to the major scientific questions posed for PEP III in the PANASH Report and the PAGES Implementation Plan,

- strengthen the development of thematic working groups and establish strategies for improving their efficiency in the area of data acquisition,

- stimulate the further development of regional PEP III coordination committees,

- lay the ground work for ensuring effective data management and integration.

Some thirty oral communications were presented as well as a comparable number of posters. The oral presentations focused on major PEP III objectives and

PEP III: the Paris-Bierville Workshop (F. Gasse)

1996-1997 Activites of CAPE (G. Miller, A. Elverhoi, S. Hicks)

PAGES Calendar

The IMAGES ocean coring and scientific cooperation efforts; Selected results (L. Labeyrie et al.)

\section{1st IGBP PAGES Open Science Meeting}

PACES Scientific Highlight:

The last Glacial Period: rapid changes in air temperature and ocean hydrology (L. Labeyrie, E. Cortijo) 


\section{EDITORIAL}

The main foci of the present Newsletter are the Pole-Equator-Pole Transect that runs through Europe and Africa (PEP III) and the International Marine Global Change Study (IMAGES).

P PEP III poses formidable logistic and scientific challenges. It spans extremes in terms of existing data.

In many parts of Western and Central Europe the need to coordinate and assimilate the results already available from published studies is at least as urgent as the need for new research.

By contrast, the record of past environmental change in vast areas of Africa is poorly documented and there is an over-riding need to expand the data base through new research. This contrast is mirrored in problems of access and logistic support for field and laboratory research in many African countries. There are also stark contrasts in the types of natural archives available for study along the full length of the transect. In the north, high resolution records, for the Holocene at least, exist in lake sediments, tree rings, peat and documentary records. In many arid and semi-arid regions on either side of the humid tropics, ground-water and discontinuous sedimentary archives are the main sources of data, but they provide a much lower resolution record and one that often fails to bring the paleo-record up to the present day. On the other hand, the lands south of the limit of the last glaciation provide quantitative evidence for the nature of lower latitude climates in glacial times and these are of outstanding significance in climate model development and validation. Moreover, the Sahara and Sahel regions provide some of the world's most dramatic evidence for massive hydrological fluctuations during the Holocene. This forms a vital antithesis to the polar perspective of a relatively stable Holocene climate. The significance of the evidence for major hydrological fluctuations in much of Africa is hightened by the vulnerability of ecosystems and human populations in the region.

Even within Europe, especially in the Mediterranean area where it is often difficult to disentangle human impacts from responses to climatic change, there is an urgent need to reconstruct the antecedents of fragile, stressed ecosystems.

The Workshop held in Bierville in September 1996 was a major landmark in responding to the challenges posed by PEP III. The present Newsletter highlights the outcome of this Meeting and subsequent progress.

The IMAGES programme is co-sponsored by PAGES and SCOR, the Standing Committee on Oceanic Research.

IMAGES is now at the stage where its Science Plan has been published and its organizational structure approved by both SCOR and IGBP. Results of the highest quality from the first IMAGES cruise have already been demonstrated, notably at the Fall AGU Meeting in San Francisco last December. A crucial aspect of the IMAGES strategy is to target high resolution records from parts of the world's oceans of particular significance in terms of energy transfer, productivity or linkage to other aspects of the earth system. Emphases on multiproxy records and on developing connections between marine and terrestrial sequences are of vital importance and here IMAGES is also leading the way and setting new standards for these endeavours.

The present Newsletter profiles some of the recent achievements of IMAGES and outlines its plans for the near future. linkages within and outside the PAGES framework, key scientific questions for the PEP III community as a whole, the potential contribution of specific regions and archives to PEP III and the future organization of PEP III activities at regional and national scale. The posters illustrated scientific results from specific sites and methods.

Several working-group meetings were held from which emerged a series of recommendations. Some of these are summarised briefly in the text that follows and they will form the main thrust of the final Workshop Report. The text and illustrative material that follows is selective rather than comprehensive. It is intended to give a flavour of the Meeting, to introduce the PAGES community as a whole to some of the challenges and opportunities that lie ahead for PEP III scientists and to foreshadow the Workshop Report being prepared for publication later this year.

\section{- Time Stream I studies in PEP III}

The report from this group recognized at the outset the desirability of high temporal resolution: seasonal wherever possible, though many valuable records will not achieve better than decadal resolution and some significantly less. Several methodological themes were emphasized, notably:

- the need to determine and make clear the true resolving power of any given archive and the extent to which this may have varied through time,

- the vital role of chronology and the need to adopt a multiple approach to developing the time frame in situations where absolute chronology is not available

- the need for replication of data with a view to reducing noise and revealing clearer records of underlying forcing mechanisms

- the essential role of calibration, in the time domain wherever possible, in order to reduce reliance on spatially derived relationships

- the strong desirability of placing realistic confidence limits on paleoclimate reconstructions

- the problems posed by reliance on the recent period of maximum human impact for calibration of paleodata against modern instrumental records

Emphasis was also placed on the potential importance of hitherto under-utilized archaeological data, especially from sites and regions that can provide high resolution records and good chronologies. This suggestion was further amplified in plenary session with special reference to the tufa deposits of the Kharga Oasis (Egypt) and the region of the Egyptian Sahara and the Nile Valley. 


\section{- Subsurface waters as Archives of paleoclimate}

The working group report and individual papers highlight the importance of subsurface waters as archives over major parts of the PEP III Transect. Despite their relatively poor temporal and spatial resolution and inevitable uncertainties in chonological control, noble gas and stable isotope records from the saturated zone, notably from confined aquifers, have been used to provide vital quantitative data for testing GCM reconstructions of past climate, especially for the Last Glacial Maximum. There is also a strong possibility that chlorine profiles from the unsaturated zone may provide important paleohydrological records in cases where the essential criteria are met. These criteria relate to the depth of the unsaturated zone between root layer and capillary fringe, the moisture content of the unsaturated zone, virtual absence of mixing of waters and a reasonably constant input of chlorine over time. The main overall conclusion of the group was to re-emphasize the special importance of subsurface water studies in large parts of the Transect where few other reliable archives exist. The formation of a Subsurface Water Working group will ensure the further development of research in these areas.

\section{- PEP III and PMIP}

Presentations at the Meeting and subsequent sessions at the recent European Geophysical Society Meeting in Vienna have begun to highlight the importance of parts of the PEP III Transect within the Paleoclimate Modeling Intercomparison Project (PMIP). The primary aim of PMIP is to determine the extent to which the simulated results from AGCM's are model dependent. The main focus is on simulations for the Last Glacial Maximum (ca.21kyr BP) and the midHolocene period ca.6kyr BP. One of the most dramatic findings so far is that although there is reasonably good comparability between the output from different modeling groups for the $6 \mathrm{kyr}$ "snapshot", there are serious discrepancies between the model reconstructions and the paleodata. This is most clearly apparent for the Sahara/Sahel region where the models fail to reconstruct conditions consistent with the paleorecords of high lake levels at this time. This in turn has provided an improved basis for parameterization of the models, using more realistic terrestrial biospheric and hydrological boundary conditions for the region. The task of reconciling models and data is far from over and this single example shows how crucial data from PEP III are for making the best possible combined use of data and models to improve eventual predictive capability.



Noble gas temperature as a function of corrected radiocarbon age derived from the Stampriet aquifer, Namibia

Under favorable conditions, the concentrations of atmospheric noble gases dissolved in groundwater of confined aquifers reflect the mean annual ground temperature at the time of recharge. The record shown indicates that the mean annual temperature in Namibia was about $5.3^{\circ} \mathrm{C}$ lower during the last glacial maximum as compared to today (Stute and Talma, 1997).

(Taken from: M. Stute, M., and Talma, S. (1997) Glacial temperatures and moisture transport reoimes reconstructed from noble gases and $\delta^{18} \mathrm{O}$, Stampriet aquifer, Namibia. In: Isotope techniques in studying past and current environmental changes in the hydrosphere and the atmosphere, IAEA, Vienna, in press).

\section{- Particular archives and proxies: peat, pollen, speleothems and loess.}

Several presentations were devoted to the role of particular archives and methods in the PEP III Transect.

Peat deposits occur in N W Europe, at high altitude in tropical environments and in lake margin environments, eg as Papyrus swamps. Rainwater-fed peatlands are currently under investigation as indicators of past variations in surface wetness, hence hydrological balance. They and other types of peat contain a wealth of biological and geochemical indicators of past environmental conditions. Moreover, they often have advantages over lake sediments when it comes to extablishing chronologies by either radiocarbon or tephra analysis. Their main role will be on Stream 1 or at most mid- to late-Holocene timescales though there are exceptions. The importance of replicating results in order to distinguish climatic responses from those reflecting more site-specific effects was stressed.

Several papers illustrated the importance of pollen analytical information across the whole range of timescales and throughout the Transect. One of the key developments associated with the Meeting was the establishment of an African Pollen Data Base to complement the well established European Pollen Data Base. This opens up access to data across the whole range of PEP III and promises to make possible the much more widescale development of pollen-based paleoclimate reconstructions.

One of the most promising concepts for development within PEP III is a transect of high resolution speleothem records. Such records may be available for the whole of PEP III from $69^{\circ} \mathrm{N}$ in Arctic Norway to $34^{\circ} \mathrm{S}$ in South Africa. They provide the basis for both detailed chronologies (Th/U) and strong climate-related signatures from stable isotopes, growth laminae and organic matter. In order to exploit the limited resources of speleothem archives in a way that both maximises their value within PEP III and respects the need for conservation, the Speleothem PEP (SPEP) has been launched as a special initiative.

The paleorecord in loess and related aeolianite sediments is also of importance within PEP III. The best know loess deposits within the Transect are mostly within Eastern Europe and many of these are currently under intensive study, especially from the point of view of their magnetic properties. Although discontinuities and pedogenic overprinting make these archives less attractive than the classic Chinese loess sections, they are neverthless of considerable interest, especially where they can be closely linked to other paleoarchives. Moreover, other loess sequences, for example in France and Tunisia, 
Ancient shorelines and lacustrine sediments in many tropical Africa lakes witness climate changes undergone in tropical Africa. The hypersaline lake Asal (Diibouti) and its salt plain extended $50 \mathrm{~m}$ above its present level 3000 years ago, as seen above, and $300 \mathrm{~m}$ higher than today 8000 years ago.

(Photo: F. Gasse)

may provide comparable sequences within the Stream II timeframe. There is a need to establish a database of presently known and investigated loess sections so that regional comparisons can be made and key sites and time intervals targeted.

\section{- National and regional groups}

Alongside the thematic Working Groups, PEP III has established National and Regional Working Groups. Reports from these were presented and their importance emphasized, especially in the context of Eastern Europe. One of the most exciting regional developments is the establishment of the PAGES Regional Reseach Centre in the University of Nairobi, Kenya. This Centre is working with START to implement a modern, efficient data and information system that will more effectively link African paleoscientists with the world-wide community through electronic communications. One of the central research tasks of the PAGES RRC is its contribution to the coordination of the East African Lakes (IDEAL) programme, though it also has an important research role in relation to the GCTE Miombo Transect, paleomonsoon phenomena in Africa, the study of crater lakes and the whole wealth of paleoarchives in the region.

\section{- Data storage and management}

The Meeting also gave preliminary consideration to the issue of data storage and management. Key points that were emphasized included:

- compatibility with the World Data CentreA/ PAGES Data Base in Boulder Colorado - development of a PEP III communication node at MEDIAS FRANCE

- the need to optimize links with existing data bases such as those developed to exploit data within particular specialisms

- the desirability of creating an open and easily incremental relational data base

- the over-riding importance of broadly based community discussion and consent in the creation, control and administration of a PEP III data base.

\section{Françoise Gasse}

Laboratoire d'Hydrologie et de Géochimie Isotopique URA CNRS 723

Université de Paris XI

91405 Orsay, France

e-mail: gasse@geol.u-psud.fr
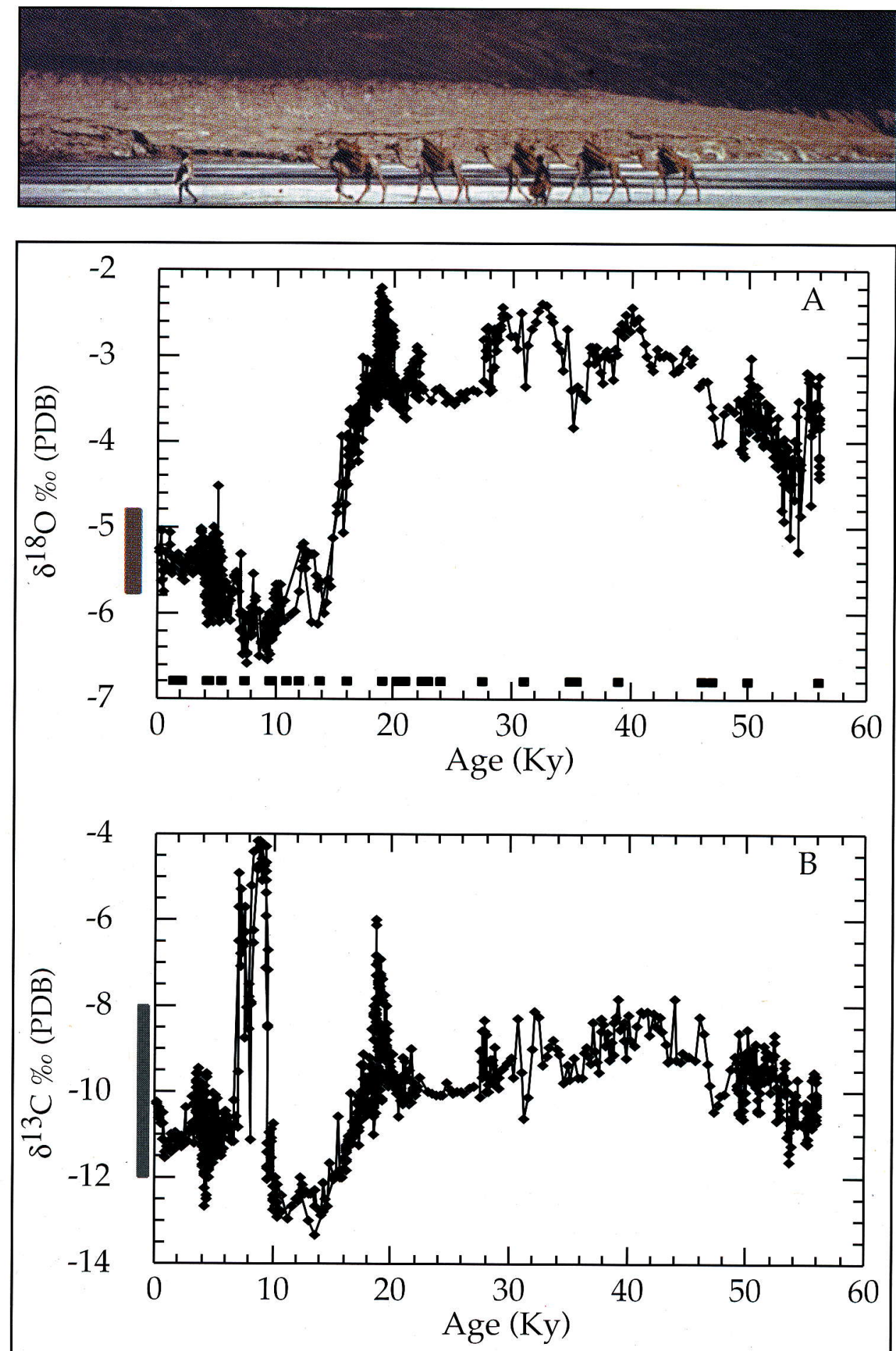

$\delta^{18} \mathrm{O}(\mathrm{A})$ and $\delta^{13} \mathrm{C}(\mathrm{B})$ variations of speleothems from the Soreq Cave (Israel) extending to $58 \mathrm{Ky}$. The squares plotted in A show the ${ }^{230} \mathrm{Th}$-U ages. The vertical bars show the present-day isotopic compositional ranges.

(Taken from Bar-Matthews M., Ayalon, A and Kaufman A. (1997) Paleoclimate evolution in the Eastern Mediterranean region during the last 58,000 yr as derived from stable isotopes of speleothems (Soreq Cave, Israel). Proceedings of the International Symposium on Isotope Techniques in the study of past and current environmental changes in the hydrosphere and the atmosphere. IAEA, Vienna, P. Murphy (Editor) In press. These diagrams present a continuous stable isotopic record obtained from cave deposits (speleothems). The studied cave (Soreq Cave) is located $60 \mathrm{~km}$ inland from the Israeli Mediterranean coast. The stable isotopic record provides a detailed insight into the climatic evolution of the late Pleistocene and Holocene, and that it is the eastern Mediterranean reflection of global climatic conditions.

The paleoclimatic interpretations of this record are given in the reference cited above, and also in: Bar-Matthews M., Ayalon, A. and Kaufman, A., 1997. Late Quaternary paleoclimate in the eastern Mediterranean region from stable isotope analysis of speleothems at Soreq Cave, Israel. Quaternary Research 47, 155-168. 